\title{
STRATEGIC TRADE POLICY WHEN FIRMS CAN INVEST ABROAD: WHEN ARE TARIFFS AND QUOTAS EQUIVALENT?
}

\author{
James A. LEVINSOHN* \\ University of Michigan, Ann Arbor, MI 48109-1220. USA
}

Received October 1987, revised version received October 1988

\begin{abstract}
This paper investigates the equivalence of tariffs and quotas when the market in question is imperfectly competitive and open to direct foreign investment. The absence of a foreign supply response under a quota, so critical to the analysis of the differential impact of tariffs and quotas under imperfect competition, is called into question by the potential occurrence of direct foreign investment. The paper proves the equivalence of optimal tariffs and quotas when the markets are oligopolistic and open to direct foreign investment.
\end{abstract}

\section{Introduction}

The ecivience of tariffs and quotas in a perfectly competitive world is well understood. It is by now equally well known that the presence of a monopoly may destroy the tariff-quota equivalence. While these are informative limiting cases, mich international trade is conducted in markets that lie somewhere between the extremes of pure competition and monopoly. This trade is often characterized by large, frequently multinational players who recognize their influence on markets and hence act strategically. Recent developments in trade theory have explored how trade policy works in this setting. This work is nicely surveyed in Grossman and Richardson (1985).

Most of the recent work on trade policy with imperfect competition has looked at various tariff/subsidy schemes. By concentrating on prices, as opposed to quantities, as policy instruments, researchers have made an important choice. While under perfect competition there will be an equivalent quota associated with any tariff, under imperfect competition this need not be the case. Bhagwati (1965) first noted this point. He showed that a tariff might dominate a quota or vice versa depending on the basis for comparison (same imports or same total consumption) and on where the monopoly was located. While the existence of a competitive fringe is an

*I have benefited from the insightful comments and suggestions of Alan Deardorff, Avinash Dixit, Gene Grossman, Dani Rodrik, and two anonymous referees to whom I am grateful. 
essential elein nt of Bhagwati's model, ${ }^{1}$ the asymmetric foreign supply response to a tariff and a quota is at the heart of the nonequivalence result. Under a tariff, the foreign producer can still increase output while under a binding quota, it cannot.

Krishna (1983) was among the first to investigate qrotas in an oligopoly setting. Her analysis provided yet another example of nonequivalence between tariffs and quotas. Using a game theoretic framework in which firms played strategically against other firms but took goverrment actions as given, Krishna showed that a quota might serve as a facilitating device while a tariff would not. She demonstrates that in a Bertrand duopoly setting, each firm would like to raise its price if it were sure that its rival would do likewise. Under a quota, it is irrational for a firm to lower its price in order to gain market share since quotas would bind. Quotas, then, allow firms to credibly precommit to higher prices. Like Bhagwati's results, Krishna's exploit the lack of a foreign supply response imposed by a quota but not by a tariff. ${ }^{2}$

In Krishna's introduction, she writes:

Most of the literature has dealt with the two polar cases of monopoly and perfect competition, neglecting the strategic interaction crucial to the analysis of oligopoly. Such interaction between firms is a dominant feature of many markets, especially in some international markets in which large multinationals operate.

Her work, though, like much of the analysis of tax based policies, ignores the possible multinational aspects of the game firms play. In this paper I consider the tariff-quota equivalence question in a setting which explicitly accounts for the possibility of direct foreign investment (dfi).

The absence of a foreign supply response under a quota, so critical to the analysis of the differential impact of tariffs and quotas under imperfect competition is called into question by the potential occurrence of dfi. The credible precommitment permitted by a government imposed quota is crucial to Krishna's analysis. Yet when the possibility of dfi exists, the key assumption of no foreign supply response to a quota may no longer hold. Wuiie a foreign producer may not be abie to increase local exportable output

\footnotetext{
${ }^{1}$ If a monopolist does not face a fringe of competitive suppliers, tariffs and quotas will be equivalent. That is, if the monopolist is a world, as opposed to domestic, monopolist, Bhagwati's result does not hold.

${ }^{2}$ Sweeney (1985) recently studied tariffs and quotas in a conjectural variations oligopolistic setting. He noted that quotas in effect change a firm's conjectures in a way that tariffs do not. This is because the rational firm's conjectures will be conditioned on the type of policies its competitors face. While there are problems in trying to model a sequential and hence dynamic process using conjectural variations, the underlying idea of the $\mathrm{CV}$ approach is the same as Bhagwati's and Krishna's. That is, there is no foreign supply response to a binding quota while such a response exists for a tariff.
} 
under a binding quota, the firm may produce the additional output in the home country. In this case, a qurta is no longer a facilitating device, and many of the strategic interactions that differentiate a quota from a tariff disappear.

The rest of this paper is organized as follows. Section 2 presents a diagrammatic analysis of tariiff-quota comparisons in the presence of dfi. This section provides a useful taxonomy for the general model of section 3 . Section 2 also provides some intuition about the results of section 3. In that section, a general oligopoly model with dfi is developed. The generality extends to the number of firms and their mode of conduct. In this setting, the tariff-quota nonequivalence of Bhagwati and Krishna is reconsidered. In particular, the optimal profit-shifting tariff is compared to the optimal profitshifting quota. Section 4 relaxes assumptions about firms' cost functions and reconsiders the results of section 3 . A brief summary is given in section 5 .

\section{A diagrammatic analysis of tariff-quota comparisons}

Consider a market in which a foreign monopolist is the sole supplier of a good in the home-country market. ${ }^{3}$ Fig. 1 represents the market for the foreign good in the usual space of own price and quantity. The foreign monopolist faces the demand schedule $D$ and the corresponding marginal revenue schedule $M R$.

In fig. 1 it is well known that the optimal tariff is positive, as the home country can improve its welfare by extracting monopoly rents from the foreign country in excess of the lost consumer surplus. ${ }^{4}$ This result requires only that $M R$ be more steeply sloped than the linear $D$. It is noteworthy that some positive tariffs are welfare improving. Since it is rational to impose such a tariff, (non)equivalence results are meaningful in a way they might not be if the imposition of a tariff was itself economically is rational. For example, the equivalence of tariffs and quotas in the perfectly competitive paradigm begs the question of why the tariff or quota is present in the first place.

Initially, the foreign firm produces only in the foreign country (this will be referred to as foreign production) at constant marginal cost $M C^{\text {for }}$. The assumption of contrast marginal cost is not incidental. While it simplifies the analysis, it is also the logical choice. If marginal cost were increasing, one might ask why additional plants, foreign or domestic, do not already exist. (This analysis, like its predecessors, glosses over the implications of large

\footnotetext{
${ }^{3}$ As stated in footnote 1 , the optimal tariff and optimal quota are equivalent in this case when dfi is not possible, since there is no competitive fringe "ad the monopolist is a global, as opposed to domestic, monopolist. Nevertheless, this framew $\mathrm{c}_{2}$. :. provides a very useful taxonomy for the more general oligopoly model of section 3 .

${ }^{4}$ This result and related others have been demonstrated in a series of pape $s$ by Brander and Spencer. The flavor of these results is in Brander and Spencer (1984).
} 


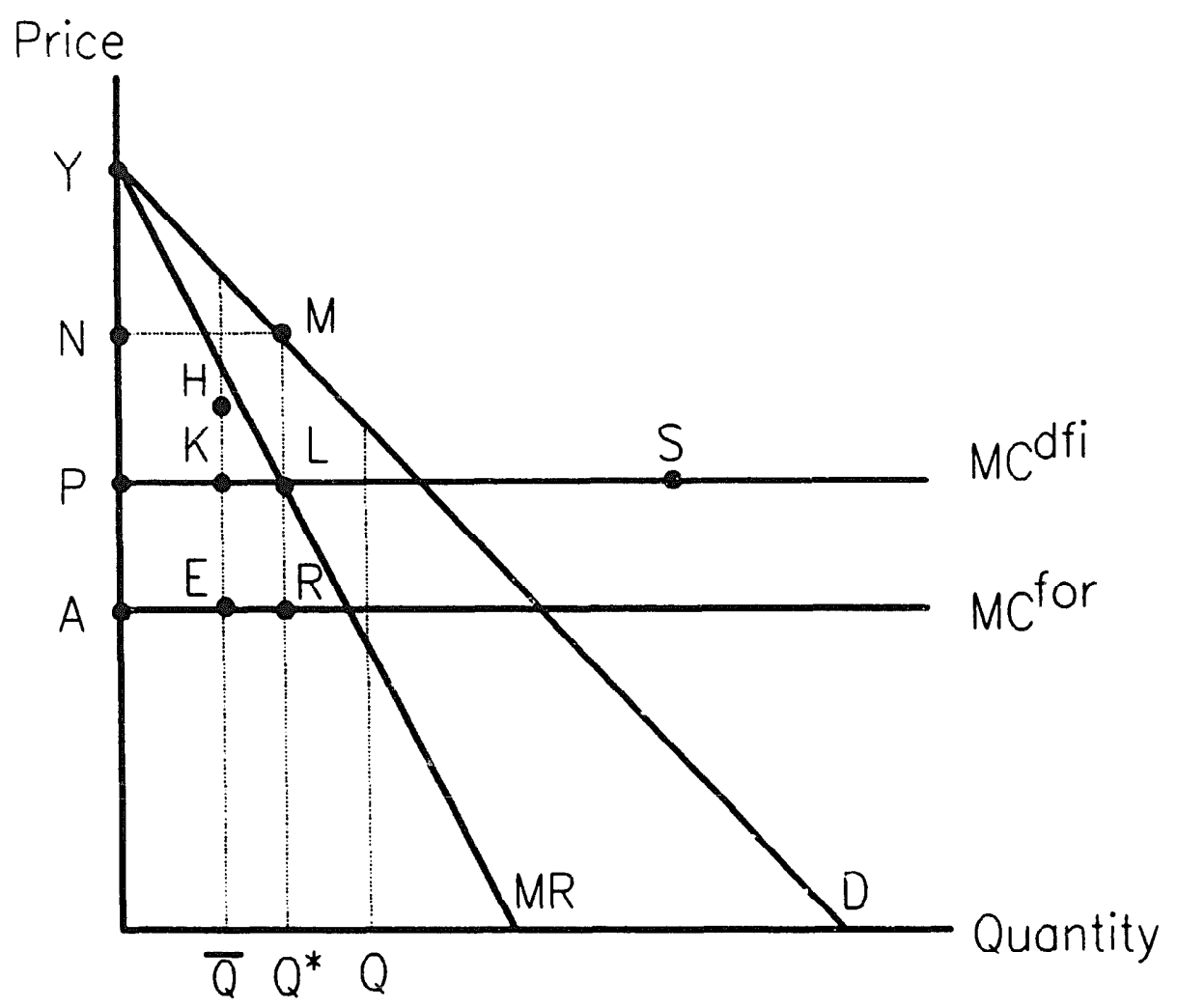

Fig. 1

fixed costs.) If marginal costs were decreasing, a new set of issues for strategic trade policy arises. ${ }^{5}$

Now let us introduce the possibility of dfi by the foreign firm in the home country. Dfi production is assumed to be a perfect substitute for non-dfi production. For example, the consumer is assumed to be indifferent between a Honda Accord built in Ohio and the same model manufactured in Japan. The marginal cost of production under dfi, $M C^{\mathrm{dfi}}$, also is assumed to be constant. $M C^{\mathrm{dfi}}$ must be at least as high as $M C^{\mathrm{for}}$. If this were not the case, cost minimization would preclude any foreign production. The optimal rentextracting tariff may be either at least as large as or smaller than the difference in marginal cosis. ${ }^{6}$ I compare tariffs and quotas for each case.

With inverse demand represented by $p=a-b x$ and the corstant marginal cost by $c$, the optimal rent-seeking tariff absent the possibility of dfi is given

\footnotetext{
${ }^{5}$ Krugman (1984) has shown that with increasing returns to scale, an advantage given to a firm in one market via trade or industrial policy may spill over into advantages in another market. Introducing dir $t$ foreign investment into this scenario is an interesting problem, but it obscures the more basic issues this paper addresses.

${ }^{6}$ It should be stressed that this paper focuses on comparing optimally set policies. In this sense, the equivalence results are fairly narrow. On the other hand, assuming optimizing behavior is a fairly standard premise.
} 
by $(a-c) / 3$. This tariff and the difference between $M C^{\mathrm{dfi}}$ and $M C^{\mathrm{for}}$ are exogenous to the policymaker. Whether or not the optimal tariff is greater than the difference in marginal costs is a function only of tastes and technologies.?

Some terminological clarification is useful. A tariff of $E H$ which was optimal before the possibility of dfi is termed the no-dfi optimal tariff. The tariff which is optimal after dfi is introduced is termed the cum-dfi optimal tariff.

Case 1. The optimal tariff, neglecting the possibility of dfi is at least as large as the difference in marginal costs.

Such a case is given in the figure by a tariff equal to $E H$. In the absence of dfi, the quota yielding the same level of imports is given by $\bar{Q}$. Now introduce the possibility of dfi at $M C^{\mathrm{dfi}}$. Dfi constraints the optimal tariff to a level of $A P^{8}{ }^{8}$ Any larger tariff induces dfi and no revenue is raised.

There is no cum-dfi tariff which will ensure imports of $\bar{Q}$ while a quota does just that. While this is an obvious nonequivalence, it is not a very meaningful one, since a quota of $\bar{Q}$ in the presence of dfi is not optimal. At a quota of $\bar{Q}$, the foreign producer faces a kinked $M C$ schedule given by $A E K L S$. Quota licence revenue is given by $A P K E$. While imports equal $\bar{Q}$, the amount $K L$ is produced via dfi in the home country. Toal consumption of the good is $Q^{*}$. Home welfare is given by consumer surplus and licence revenue. This is area $M N Y$ plus $P K E A$. A quota of $Q^{*}$, which corresponds to the cum-dfi optimal tariff, yields the same consumer surplus but gives strictly greater licence revenue by amount $K L R E$. The cum-dfi optimal tariff is equivalent to the cum-dfi optimal quota.

Simple jumping of a quota such as $\bar{Q}$ leads to dfi concurrent with home production even though marginal costs are constant. Without quantity restrictions, such behavior is incompatible with standard cost minimization. Seen from a different angle, the very presence of dfi as quota jumping is evidence that the quota is set at a suboptimal level.

With imperfect competition, dfi may be welfare worsening, as it may undermine optimal rent extracting trade policies.9 Although it is not obvious from the geometry of fig. 1, a revealed-preference argument shows that dfi is welfare worsening since the cum-dfi policies were feasible but not chosen when selecting the no-dfi optimal policies.

Case 2. The optimal tariff is less than the difference in marginal costs.

\footnotetext{
${ }^{7}$ As section 3 will prove, the linearity of this example is not necessary to the argument presented here. Even in a general model, the optimal policies will be functions of only tastes and technology.

${ }^{8}$ Actually, the optimal tariff is constrained to a level of AP minus epsilon. Throughout the analysis, the open set aspect of the optimal tariff will be ignored.

${ }^{9}$ Similar conclusions have been reached in perfectly competitive models by Grossman (1984) and Podrik (1987).
} 
In this case previously considered tariff-quota comparisons ${ }^{10}$ hold except that the marginal cost of dfi imposes an upper bound beyond which a quota will provoke a supply response in the form of dfi. If the cost function of dfi is similar to the cost function of domestic production, the difference in marginal costs will be small and it becomes less likely that Case 2 will obtain.

\section{A more general analysis of tariff-quota comparisons}

The previous section demonstrated that in a fairly specific setting, if the no-dfi optimal tariff exceeded the difference in local and dfi marginal costs, then the introduction of dfi made the optimal rent-extracting tariff and the optimal rent-extracting quota equivalent policies. In section 2 , there was a foreign monopolist facing a linear demand schedule. In this section, I generalize the diagrammatic results by considering a differentiated-product oligopoly in which firms face general demand schedules and market conduct is not restricted. This latter generalization is of some significance, as Eaton and Grossman (1986) have shown that choice of market conduct is often key to characterizing optimal policies.

I consider tariff-quota equivalence in the presence of dfi when firms compete only in the home market. The restrictive assumption that is in part carried over from section 2 is that marginal cost must be constant in the neighborhood where production actually occurs. The reasons are the same as before. With upward-sloping marginal costs, one must consider why another plant does not already exist. (The ramifications of upward sloping marginal costs are discussed in section 4.) With downward-sloping marginal costs, an entirely new set of issues arises and these may obscure the original intent of the an tlysis.

The more general setting described above is of more than just theoretical interest as it describes the U.S./Japanese automobile market fairly accurately. U.S. and Japanese cars are certainly differentiated products. They are produced with constant marginal costs by a small number of very large firms in each country. These firms compete with each other almost solely in the U.S. market. Furthermore, the market has been subject to tariffs and, more recently, quotas. ${ }^{.}$Completing the picture, dfi in the U.S. by Japanese firms is a rapidly growing phenomenon.

\subsection{The set up}

It is useful to establish some notation at the outset. Let:

\footnotetext{
${ }^{10}$ These comparisons will depend on market structure. The relevant comparisons are Bhagwati (1965) if the rest of the world forms a competitive fringe, Krishna (1983) if the rest of the world has few firms, and the result in footnote 1 if there are no foreign producers.

11 The model, though, assumes that quota rents accrue to the home country. This is not the case with the VERs on Japanese auto exports to the United States.
} 


$$
\begin{aligned}
& n_{1}=\text { number of domestic firms, and } \\
& n_{2}=\text { number of foreign firms. }
\end{aligned}
$$

I consider a symmetric market structure in which firms within a country are identical. Dfi production represents an increase in output but it is not an increase in the number of firms. Output is given by:

$$
\begin{aligned}
& q_{1}=\text { output of a firm in industry } 1 \text {, } \\
& q_{2}=\text { output of a firm in industry } 2 \text {. }
\end{aligned}
$$

$q_{2}=q_{2 \mathrm{f}}+q_{2 \mathrm{~d}}$, where $q_{2 \mathrm{f}}$ is production by foreign firms in the foreign country and $q_{2 d}$ is dfi production. Let:

$$
\begin{aligned}
& Q_{1}=n_{\mathrm{i}} q_{1}, \\
& Q_{2 \mathrm{~d}}=n_{2} q_{2 \mathrm{~d}}, \\
& Q_{2 \mathrm{f}}=n_{2} q_{2 \mathrm{f}} \text { and } Q_{2 \mathrm{~d}}+Q_{2 \mathrm{f}}=Q_{2} .
\end{aligned}
$$

Cost functions are:

$$
\begin{aligned}
& C^{1}=c\left(q_{1}\right), \\
& C^{2}=c\left(q_{2 \mathrm{f}}, q_{2 \mathrm{~d}}\right) .
\end{aligned}
$$

Assumption 1. Marginal costs, denoted $c_{1}, c_{2 \mathrm{~d}}$, and $c_{2 \mathrm{f}}$, are constant and $c_{2 \mathrm{~d}}>c_{2 \mathrm{f}}$.

Let $v_{i j}$ be firm $j$ 's conjecture of firm $i$ 's quantity response to a change in its own quantity $(i, j=1,2)$. The conjectural variations $(C V)$ parameter is used in this context as a flexible parameter which can represent myriad market conducts. It is no more than a convenient parameterization.

The home country's utility function is given by $U=U\left(Q_{1}, Q_{2}\right)$. Inverse demands are:

$$
\frac{\partial U}{\partial Q_{1}}=P^{1}\left(Q_{1}, Q_{2}\right) \text { and } \frac{\partial U}{\partial Q_{2}}=P^{2}\left(Q_{1}, Q_{2}\right)
$$

Subscripts on $P^{1}$ and $P^{2}$ will denote partial derivatives.

Before dfi is introduced, the home country is able to freely set a specific 
tariff $t$ on imports and a specific subsidy $s$ on home production. Finally, I make the following two assumptions.

Assumption 2. The no-dfi optimal tariff is profitably jumped. (This corresponds to Case 1 of the diagrammatic analysis.)

Assumption 3. Home welfare is continuous and strictly concave in policy tools.

This assumption holds in the linear case (as in section 2) and is a natural extension thereof. The assumption is restrictive in that it disallows cases in which, as one goes from no tariff to the optimal tariff, welfare falls then rises.

\subsection{Proof of tariff-quota equivalence}

I prove that the optimal tariff and quoia are equivalent in two steps. In step 1, I characterize the optimal tariff and subsidy combination. It is important to consider subsidy schemes. A subsidy will generally be needed, in addition to a tariff, to attain a first-best optimum. This is true with or without dfi, because one needs two instruments to control cptimally for two targets. One of these targets is the price-marginal cost gap in the production of home firms; the other is the strategic distortion which gives rise to profit shifting. Without dfi, the production subsidy addresses the first target, and trade policy addresses the second. Because the no-dfi optimal tariff is, by Assumption 2, profitably jumped, the no-dfi optimal tariff raises no revenue in the presence of dfi. In this sense, dfi constrains tariff setting to a level no greater than the difference in foreign marginal costs. Since the possibility of dfi blunis the efficacy of the tariff with respect to the profit-shifting objective, there will be an additional motive for employing the subsidy. The approach here follows Dixit $(1984,1986)$.

In step 2, I characterize the optimal quota and subsidy combination. Dfi does not constrain quota setting as it constrains tariff setting. Hence, the home country has an unconstrained policy tool for each quantity involved. I prove that the ability to set a binding quota has no value in terms of home country welfare. Furthermore, the solution to the optimal tariff/subsidy scheme will always be the solution of the optimal quota/subsidy scheme. This equivalence will be shown to be independent of the number of firms on either side of the market and independent of the mode of market conduct.

I then extend the equivalence by proving that the optimal tariff and quota are also equivalent when no subsidy is available.

Step 1. Here I characterize the optimal tariff/subsidy scheme. Firms choose 
outputs strategically but take government policies as given. The government maximizes national welfare conditional upon firms' profit maximization.

I first consider firms' profit maximizing behavior. By Assumption 2, the cum-dfi optimal tariff must be no greater than $c_{2 \mathrm{~d}}-c_{2 \mathrm{f}}$. (Were it greater, no revenue would be raised.) Because marginal costs are constant by Assumption 1, cost minimization precludes dfi concurrent with domestic production. Thus $q_{2}=q_{2 \mathrm{f}}$.

Firms' profit functions are given by:

$$
\begin{aligned}
& \pi_{1}=P^{1}\left(Q_{1}, Q_{2}\right) q_{1}-C^{1}\left(q_{1}\right)+s q_{1}, \\
& \pi_{2}=\left(P^{2}\left(Q_{1}, Q_{2}\right)-t\right) q_{2}-C^{2}\left(q_{2}\right) .
\end{aligned}
$$

An interior solution to an individual firm's profit maximization implies:

$$
\begin{aligned}
& \mu^{1}=\frac{\partial \pi_{1}}{\partial q_{1}}=0=P^{1}\left(Q_{1}, Q_{2}\right)+s-c_{1}+q_{1}\left(P_{1}^{1}\left(Q_{1}, Q_{2}\right) g_{0}+P_{2}^{1}\left(Q_{1}, Q_{2}\right) g_{1}\right) \\
& \mu^{2}=\frac{\partial \pi_{2}}{\partial q_{2}}=0=P^{2}\left(Q_{1}, Q_{2}\right)-t-c_{2 \mathrm{f}}+q_{2}\left(P_{1}^{2}\left(Q_{1}, Q_{2}\right) h_{1}+P_{2}^{2}\left(Q_{1}, Q_{2}\right) h_{0}\right)
\end{aligned}
$$

where

$$
\begin{aligned}
& g_{0}=\left[1+\left(n_{1}-1\right) v_{11}\right], \\
& g_{1}=n_{2} v_{21}, \\
& h_{0}=\left[1+\left(n_{2}-1\right) v_{22}\right], \\
& h_{1}=n_{1} v_{12} .
\end{aligned}
$$

These $g$ and $h$ terms reflect the mode of market conduct and the number of firms. They are treated as constants although making them functions of quantities does not affect any of the equivalence results.

Some comparative statics analysis on firms' profit maximization will be useful for the later welfare analysis. It will be helpful to introduce some new notation. Arguments of partial derivatives of the inverse demand functions will be omitted for brevity. Let:

$$
\Omega_{1}\left(Q_{1}, Q_{2}\right)=\frac{P_{11}^{2} h_{1}+P_{12}^{2} h_{0}}{n_{2}}, \quad \Omega_{3}\left(Q_{1}, Q_{2}\right)=\frac{P_{12}^{1} g_{0}+P_{22}^{1} g_{1}}{n_{1}},
$$




$$
\Omega_{2}\left(Q_{1}, Q_{2}\right)=\frac{P_{12}^{2} h_{1}+P_{22}^{2} h_{0}}{n_{2}}, \quad \Omega_{4}\left(Q_{1}, Q_{2}\right)=\frac{P_{11}^{1} g_{0}+P_{12}^{1} g_{1}}{n_{1}}
$$

This set of terms is related to the degree of concavity or convexity of the inverse demand functions. With linear inverse demands, these terms all become zero. A second set of terms deals with conjectures aggregated to an industry level. These terms are:

$$
R_{1}\left(Q_{1}, Q_{2}\right)=\frac{P_{1}^{1} g_{0}+P_{2}^{1} g_{1}}{n_{1}} \text { and } R_{2}\left(Q_{1}, Q_{2}\right)=\frac{P_{1}^{2} h_{1}+P_{2}^{2} h_{0}}{n_{2}} .
$$

Using this notation, firms' first-order conditions simplify to:

$$
\begin{aligned}
& P^{1}+Q_{1} R_{1}-c_{1}=-s, \\
& P^{2}+Q_{2} R_{2}-c_{2 \mathrm{f}}=t .
\end{aligned}
$$

Eqs. $\left(3^{\prime}\right)$ and $\left(4^{\prime}\right)$ implicitly define a one-to-one mapping between policy tools $s$ and $i$ and quantities $Q$ and $Q_{2}$. As policy tools change, firms respond by adjusting quantities. This relationship is given by totally differentiating $\left(3^{\prime}\right)$ and $\left(4^{\prime}\right)$ to give the below system:

$$
\left(\begin{array}{cc}
P_{1}^{1}+R_{1}+Q_{1} \Omega_{4} & P_{2}^{1}+Q_{1} \Omega_{3} \\
P_{1}^{2}+Q_{2} \Omega_{1} & P_{2}^{2}+R_{2}+Q_{2} \Omega_{2}
\end{array}\right)\left(\begin{array}{c}
\mathrm{d} Q_{1} \\
\mathrm{~d} Q_{2}
\end{array}\right)=\left(\begin{array}{c}
-\mathrm{d} s \\
\mathrm{~d} t
\end{array}\right) .
$$

Conditional upon Assumptions 1 throrgh 3 and firms' profit maximization, the home country sets $s$ and $t$ to maximize home welfare. Home welfare is given by consumer surplus, domestic profits, and net trade taxes. Hence:

$$
\begin{aligned}
W & =U\left(Q_{1}, Q_{2}\right)-P^{1} Q_{1}-P^{2} Q_{2}+n_{1} \pi_{1}+t Q_{2}-s Q_{1} \\
& =U\left(Q_{1}, Q_{2}\right)-P^{2}\left(Q_{1}, Q_{2}\right) Q_{2}-c_{1} Q_{1}+t Q_{2} .
\end{aligned}
$$

This implicitly defines welfare as a function of $s$ and $t$. That is:

$$
W=f\left(Q_{1}(s, t), Q_{2}(s, t), t\right) .
$$

I proceed by characterizing the optimal policy pair $\left(s^{*}, t^{*}\right)$. The home production subsidy is not constrained by the potential of dfi. Hence, $s$ is set such that 


$$
\frac{\delta W}{\delta s}=0, \text { for any tariff } t
$$

The tariff, though, is constrained in that any tariff greater than the difference in marginal costs induces dfi and hence raises no revenue. It follows from Assumption 3 that $\partial W / \partial t>0$ for a tariff set below the difference in marginal costs. The optimal cum-dfi tariff, then, is the largest tariff that does not induce difi. Hence, $t^{*}=c_{2 \mathrm{~d}}-c_{2 \mathrm{f}}$.

Eq. (8) implicitly defines the optimal subsidy coupled with the cum-dif optimal tariff. Using $t=c_{2 \mathrm{~d}}-c_{2 \mathrm{f}}$ and substituting ( $\left(^{\prime}\right)$ into (8) yields:

$$
\frac{\partial W}{\partial s}=0=\left[-s-Q_{1} R_{1}-P_{1}^{2} Q_{2}\right] \frac{\partial Q_{1}}{\partial s}+\left[c_{2 \mathrm{~d}}-c_{2 \mathrm{f}}-P_{2}^{2} Q_{2}\right] \frac{\partial Q_{2}}{\partial s} .
$$

Using system (5) to solve for $\partial Q_{1} / \partial s$ and $\partial Q_{2} / \partial s$ and solving for $s$ gives:

$$
s^{*}=-Q_{1} R_{1}-Q_{2} P_{1}^{2}-\frac{\left[c_{2 \mathrm{~d}}-c_{2 \mathrm{f}}-Q_{2} P_{2}^{2}\right]\left[P_{1}^{2}+Q_{2} \Omega_{1}\right]}{P_{2}^{2}+R_{2}+Q_{2} \Omega_{2}} .
$$

The optimal subsidy is a function of market conduct, number of firms, tastes, and technology. It is not in general possible to sign the expression. For the special case of Cournot competition and linear inverse demands,

$$
\frac{\delta s}{\delta\left(c_{2 \mathrm{~d}}-c_{2 \mathrm{f}}\right)}=\frac{P_{1}^{2}}{P_{2}^{2}+R_{2}}<0 .
$$

This accords with intuition. As the difference in marginal costs contracts, the cum-dfi optimal tariff becomes more constrained. Since the profit-shifting ability of the tariff is more constrained, the home production subsidy acts to capture some of the foreign oligopoly rents that the tariff no longer can.

Step 2. I next characterize the optimal quota/subsidy scheme and show that it is equivalent to the optimal tariff/subsidy scheme of step 1.

The home government may set two policy tools - a quota on $Q_{2 \mathrm{f}}$ and a subsidy on home production. ${ }^{2}$ As in the tariff/subsidy scheme, I assume $c_{2 \mathrm{~d}}-c_{2 \mathrm{f}}$ is less than the no-dfi optimal tariff. The dual of this assumption is

${ }^{12}$ The modelling of the quota below implicitly assumes that a quota on overall imports translates into a fixed ceiling on the exports of each foreign firm. This is a reasonable assumption if either: the foreign government allots exports among the foreign firms based on pre-quota production levels (and the quota was not weit ambicipated), or the guota acts as a focal point around which the foreign firnts can coordinate their actions. 
that dfi, if it existed, would occur at the no-dfi optimal quota. Unlike the case of the tariff, the difference in foreign marginal costs does not constrain the choice of the quota. This corresponds to the diagrammatic case in which no tariff could ensure imports of $\bar{Q}$ while a quota did just that. The cost differential, $c_{2 \mathrm{~d}}-c_{2 \mathrm{f}}$, now sets the maximum price a foreign firm would be willing to pay for a quota licence. So that comparison with the tariff/subsidy scenario is valid, I assume quotas are auctioned to foreign producers.

As in step 1, I first consider firms' profit maximization and then characterize optimal policy conditional on firms' optimizing behavior. Since foreign firms pay $c_{2 \mathrm{~d}}-c_{2 \mathrm{f}}$ for the quota licence on non-dfi production, a foreign firm's profit function is now given by:13

$$
\pi_{2}=\left[P^{2}\left(Q_{1}, Q_{2}\right)-\left(c_{2 \mathrm{~d}}-c_{2 \mathrm{f}}\right)\right] q_{2 \mathrm{f}}+P^{2}\left(Q_{1}, Q_{2}\right) q_{2 \mathrm{~d}}-C^{2}\left(q_{2 \mathrm{f}}, q_{2 \mathrm{~d}}\right) .
$$

A home firm's profit function is unchanged from (1) as is its first-order condition $-(3)$ or $\left(3^{\prime}\right)$.

The foreign firms maximize profits only with respect to $q_{2 \mathrm{~d}}$. They take $q_{2 \mathrm{f}}$ as given since the quota binds and is exogenously set. Foreign profit maximization, then, implies:

$$
\begin{aligned}
\frac{\partial \pi_{2}}{\partial q_{2 \mathrm{~d}}}=0 & =P^{2}-c_{2 \mathrm{~d}}+q_{2}\left[P_{1}^{2} h_{0}+P_{2}^{2} h_{0}\right] \text { and } q_{2}=q_{2 \mathrm{f}}+q_{2 d} \\
& =P^{2}-c_{2 \mathrm{~d}}+\left(Q_{2 \mathrm{~d}}+Q_{2 \mathrm{f}}\right) R_{2} .
\end{aligned}
$$

Eqs. $\left(3^{\prime}\right)$ and $\left(11^{\prime}\right)$ implicitly define a mapping between policy tools $s$ and $Q_{2 \mathrm{f}}$ and free quantities $Q_{1}$ and $Q_{2 \mathrm{~d}}$. As the government changes policies, quantities adjust. For foreign firms, this relationship is represented by totally differentiating $\left(11^{\prime}\right)$. This gives:

$$
\begin{aligned}
& {\left[P_{1}^{2}+\left(Q_{2 \mathrm{~d}}+Q_{2 \mathrm{f}}\right) \Omega_{1}\right] \mathrm{d} Q_{1}+\left[P_{2}^{2}+\left(Q_{2 \mathrm{~d}}+Q_{2 \mathrm{f}}\right) \Omega_{2}+R_{2}\right]} \\
& \quad \times\left[\mathrm{d} Q_{2 \mathrm{~d}}+\mathrm{d} Q_{2 \mathrm{f}}\right]=0 .
\end{aligned}
$$

As quantities change, $P^{2}$ changes. Since $\mathrm{d} P^{2}\left(Q_{1}, Q_{2}\right)=p_{1}^{2} \mathrm{~d} Q_{1}+P_{2}^{2} \mathrm{~d} Q_{2},(12)$ can be written:

\footnotetext{
${ }^{13}$ It is well known that an equilibrium in pure strategies may not exist for Bertrand behavior in the presence of a quota. Krishna then shows an equilibrium will exist in mixed strategies. Nonexistence of equilibria in pure strategies is rot a problem when dfi occurs. To understand why, it helps to understand why a purc strategies equilibrium in the presence of a quota might fail to exist in the first place. A binding quota acts like a binding capacity constraint. Firms playing Nash in prices may cycle endlessly around the capacity constraint or quota. Introducing dfi is analogous to removing the capacity constraint that is causing the cycling behavior. An equilibrium in pure strategies will exist when the quota is jumped via dfi.
} 


$$
\mathrm{d} P^{2}=\left(-Q_{2} \Omega_{1}\right) \mathrm{d} Q_{1}-\left(Q_{2} \Omega_{2}+R_{2}\right) \mathrm{d} Q_{2} .
$$

Finally, (12) can be manipulated to show how free quantities change as the quota is adjusted. This gives:

$$
\mathrm{d} Q_{2 \mathrm{f}}=-\frac{P_{1}^{2}+Q_{2} \Omega_{1}}{P_{2}^{2}+Q_{2} \Omega_{2}+R_{2}} \mathrm{~d} Q_{1}-\mathrm{d} Q_{2 \mathrm{~d}}
$$

Eqs. (13) and (14) will be useful for the home welfare maximization to which I now turn.

Home welfare is given by consumer surplus, domestic profits, and licence revenues:

$$
W=U\left(Q_{1}, Q_{2}\right)-P^{1} Q_{1}-P^{2} Q_{2}+n_{1} \pi_{1}+\left(c_{2 \mathrm{~d}}-c_{2 \mathrm{f}}\right) Q_{2 \mathrm{f}}-s Q_{1}
$$

Unlike the tariff case, revenue is possible in the presence of dfi, hence $Q_{2 \mathrm{~d}}$ need not equal zero. An incremental change in welfare is given by:

$$
\mathrm{d} W=\left(P^{1}-c_{1}\right) \mathrm{d} Q_{1}-\left(Q_{2 \mathrm{~d}}+Q_{2 \mathrm{f}}\right) \mathrm{d} P^{2}+\left(c_{2 \mathrm{~d}}-c_{2 \mathrm{f}}\right) \mathrm{d} Q_{2 \mathrm{f}} .
$$

Eq. (16) implies a possible first-best situation since there is an unconstrained policy tool for each of the free quantities $-Q_{1}$ and $Q_{2 \mathrm{~d}}$.

Substituting $\left(3^{\prime}\right),(13)$ and (14) into the welfare maximand, (16), and simplifying gives:

$$
\begin{aligned}
\mathrm{d} W= & \left(-Q_{1} R_{1}-s+\left(Q_{2}\right)^{2} \Omega_{1}-\left[\left(Q_{2}\right)^{2} \Omega_{2}+Q_{2} R_{2}+c_{2 \mathrm{~d}}-c_{2 \mathrm{f}}\right]\right. \\
& \left.\times\left[\frac{P_{1}^{2}+Q_{2} \Omega_{1}}{P_{2}^{2}+Q_{2} \Omega_{2}+R_{2}}\right]\right) \mathrm{d} Q_{1}+\left(c_{2 \mathrm{f}}-c_{2 \mathrm{~d}}\right) \mathrm{d} Q_{2 \mathrm{~d}} .
\end{aligned}
$$

The second term in (17) is very informative. Since $c_{2 \mathrm{~d}}>c_{2 \mathrm{f}}$, dfi enters negatively in home welfare. The ability to set a strictly binding quota which provikes dfi, then, is of no benefit to domestic welfare. Indeed, given the assumptions of this model, the existence of $\mathrm{dfi}$ in a constant marginal cost imperfectly competitive industry is evidence of suboptimal trade policy..$^{14} \mathrm{At}$ a welfare optimum, $Q_{2 \mathrm{~d}}$ equals 0 . The quota on $Q_{2 \mathrm{f}}$ is set such that revenue

${ }^{14} \mathrm{Dfi}$, though, is often praised for the increased employment associated with it. Results atout how the equivalences of section 3 are affected by domestic employment concerns are available on request from the author. 
$Q_{2 \mathrm{f}}\left(c_{2 \mathrm{~d}}-c_{2 \mathrm{f}}\right)$ is collected but no dfi is provoked..$^{15}$ This is exactly what the cum-dfi optimal tariff accomplishes.

The first term in (17) implicitly defines the optimal subsidy that is coupled with the optimal quota. Setting the term multiplied by $\mathrm{d} Q_{1}$ equal to zero and solving for $s$ gives the optimal subsidy. Straightforward calculations show that this optimal subsidy is identical to the optimal subsidy in the tariff/ subsidy scheme of step 1 . Again, the optimal subsidy depends on the number of domestic and foreign firms and their mode of market conduct.

The tariff/subsidy scheme is completely equivalent to the quota/subsidy scheme. This result is independent of the number of firms, their market conduct, and the inverse demand system they face.

For some modes of market conduct, the optimal production subsidy associated with the optimal cum-dfi tariff or quota will be positive. Subsidizing domestic oligopolists, though, may often be politically infeasible. I next show that restricting the home production subsidy to zero does not affect the equivalence of the optimal tariff and optimal quota demonstrated above. That is, the ability to set a binding quota which provokes dfi provides no benefit to home welfare, even when a home production subsidy is unavailable.

From Assumption 3, it still follows that $\partial W / \partial t>0$ for any dfi-constrained tariff. The cum-dfi optimal tariff, then, is still $c_{2 \mathrm{~d}}-c_{2 \mathrm{f}}$. I next show '1hat the optimal quota is equivalent to this optimal tariff.

Foreign firms' profit functions and their respective first-order conditions are unchanged by restricting a home production subsidy to zero. Hence, $\left(11^{\prime}\right),(12)$, and (13) still obtain.

A home firm's profit function is now:

$$
\pi_{1}=P^{1}\left(Q_{1}, Q_{2}\right) q_{1}-C\left(q_{1}\right)
$$

Its first-order condition at an interior solution is given by:

$$
P^{1}-c_{1}+Q_{1} R_{1}=0
$$

Home welfare is still given by (15) and an incremental change in it by (16). Substituting (19), (13), and (14) into (16) now yields:

$$
\mathrm{d} W=\left[-Q_{1} R_{1}+\left(Q_{2}\right)^{2} \Omega_{1}-\left(\left[Q_{2}\right)^{2} \Omega_{2}+Q_{2} R_{2}+c_{2 \mathrm{~d}}-c_{2 \mathrm{f}}\right]\right.
$$

\footnotetext{
${ }^{15}$ Proof that this assignment does indeed achieve the optimum relies on Assumption 3. We know dfi enters welfare negatively, yet licence revenue, like the constrained tariff revenue, enters welfare positively. Hence, the sotimum is at the knife-edge described in the text. It is not possible to set $\partial w / \partial s$ and $\partial w / \partial t=0$ to explicitly solve for the optimal quota because price is a general function of quantities.
} 


$$
\left.\times\left[\frac{P_{1}^{2}+Q_{2} \Omega_{1}}{P_{2}^{2}+Q_{2} \Omega_{2}+R_{2}}\right]\right] \mathrm{d} Q_{1}+\left(c_{2 \mathrm{f}}-c_{2 \mathrm{~d}}\right) \mathrm{d} Q_{2 \mathrm{~d}}
$$

Since $c_{2 \mathrm{f}}<c_{2 \mathrm{~d}}$, dfi enters negatively into home welfare even when the subsidy is constrained to zero. The ability to set a binding quota that provokes dfi confers no welfare benefit to the home country.

As was the case when a subsidy was alloweci, the quota on $Q_{2 \mathrm{f}}$ is set such that $Q_{2 \mathrm{f}}\left(c_{2 \mathrm{~d}}-c_{2 \mathrm{f}}\right)$ is collected as licence revenue but no dfi is provoked. This is equivalent to the dfi constrained optimal tariff scenario.

\section{Increasing marginal costs and tariff-quota nonequivalence: An example}

Throughout this paper, marginal costs have been assumed to be constant. In this section I show that this assumption is essential to the general equivalence results. This is done by the use of a numerical counterexample. I consider a simple Cournot duopoly. Let firm's cost functions and marginal costs be given by:

$$
\begin{array}{ll}
T C_{1}=10+\frac{1}{2}\left(Q_{1}\right)^{2}, & c_{1}=Q_{1}, \\
T C_{2 \mathrm{f}}=10+\frac{1}{2}\left(Q_{2 \mathrm{f}}\right)^{2}, & c_{2 \mathrm{f}}=Q_{2 \mathrm{f}}, \\
T C_{2 \mathrm{~d}}=10+3 Q_{2 \mathrm{~d}}+\frac{1}{2}\left(Q_{2 \mathrm{~d}}\right)^{2}, & c_{2 \mathrm{~d}}=3+Q_{2 \mathrm{~d}} .
\end{array}
$$

As in section 3, the marginal cost schedule of dfi lies strictly above the marginal cost schedule of foreign local production. Inverse demands are given by

$$
\begin{aligned}
& P^{1}=10-\cap .1 Q_{1}-0.05 Q_{2}, \\
& P_{2}=10-0.05 Q_{1}-0.1 Q_{2} .
\end{aligned}
$$

It is no longer useful to use the taxonomy of the constant marginal cost case when calculating optimal policies. Even if the tariff is greater than $\left(c_{2 \mathrm{~d}}-c_{2 \mathrm{f}}\right), \mathrm{dfi}$ and foreign local production might coexist. Another difference relative to the constant marginal cost case is that the value of a quota licence will depend on the quantities being produced. In particular, a licence will be worth the difference in marginal custs at the equilibrium quantities. With these points in mind, it is straightforward to calculate optimal policy schemes using the same methodology explained in section 3. Using the cost functions and inverse demands from (21) and (22), resulting equilibria are given in table 1. 
Table 1

Optimal tariff/subsidy and optimal quota/subsidy schemes with increasing marginal costs: An example.

\begin{tabular}{llcc}
\hline & Free trade & Tariff/subsidy & Quota/subsidy \\
\hline Optimal subsidy & - & 1.127 & 1.061 \\
Optimal tariff & - & 3.687 & (value of licence) 4.229 \\
Optimal quota & - & - & 2.115 \\
Dfi $\left(Q_{2 \mathrm{~d}}\right)$ & 4.291 & 4.806 & 3.344 \\
Total imports $\left(Q_{2}\right)$ & 11.582 & 8.745 & 5.549 \\
Domestic production $\left(Q_{1}\right)$ & 7.851 & 8.909 & 8.990 \\
$P^{1}$ & 8.636 & 8.671 & 8.828 \\
$P^{2}$ & 8.450 & 8.680 & 9.005 \\
$\pi_{1}$ & 26.980 & 37.619 & 38.494 \\
$\pi_{2}$ & 29.200 & 6.952 & 2.351 \\
Consumer surplus & 14.335 & 11.687 & 7.984 \\
Home welfare & 41.316 & 64.524 & 55.422 \\
\hline
\end{tabular}

Table 1 illustrates several points. First, the optimal tariff/subsidy scheme is not equivalent to the optimal quota/subsidy scheme. This is due to the very different ways a tariff and a quota affect the foreign firm's profit function. In free trade, the profit maximizing foreign firm will produce where $c_{2 \mathrm{~d}}\left(Q_{2 \mathrm{~d}}\right)=$ $c_{2 \mathrm{f}}\left(Q_{2 \mathrm{f}}\right)$ at an interior solution. This implies $Q_{2 \mathrm{f}}>Q_{2 \mathrm{~d}}$ since $c_{2 \mathrm{~d}}(\cdot)>c_{2 \mathrm{f}}(\cdot)$. A tariff shifts $c_{2 f}$ upward but the foreign firm continues to produce where $c_{2 \mathrm{~d}}=c_{2 \mathrm{f}}+t$. As output expands past the point at which dfi becomes profitable, the foreign firm minimizes cost by dividing production between dfi and foreign local production. When a binding quota is in place, the foreign firm cannot divide output between its two plants. Instead, the firm must, on the margin, produce only via dfi. This results in marginal costs that rise more quickly per unit of output. Whereas with a tariff the foreign firm could in effect spread the increased marginal costs between two plants, now only one plant may produce output beyond the amount of the quota. This is why in table 1 the foreign good price is higher and foreign output and profits are lower with the quota than with the tariff. The lower $Q_{2}$ associated with a quota yields a larger $P^{1}$. While this increases domestic profits, this does not offset the loss in consumer surplus and trade tax revenue relative to the tariff scheme. Net home welfare is lower with the optimal/quota/subsidy than with the optimal tariff/subsidy.

Second, table 1 dramatically illustrates the concept of profit shifting trade policy. Foreign profits fall from 29.2 with free trade of 6.95 with a tariff and 2.35 with a quota. Home welfare in turn rises from 41.31 to 64.52 with a tariff and to 55.42 with a quota.

The results of table 1 are a specific example of tariff-quota nonequivalence. They are not a general comparison of tariffs and quotas with increasing marginal costs. The results of table 1 are sensitive to the mode of market conduct and the furictional forms used. 


\section{Summary}

Recent work on tariff-quota nonequivalence under imperfect competition has ignored the possibility that the firms concerned might be multinational. Introducing the possibility of dfi, which is often associated with multinational firms, greatly simplifies the tariff-quota comparison. Many of the strategic interactions that are difficult to model in a general way disappear when dfi is introduced into the model.

Section 2 analyzed the equivalence issue in a linear foreign monopoly model. Using a diagrammatic analysis, optimal tariffs and quotas were shown to be equivalent when the cum-dfi optimal tariff exceeded the difference between the marginal cost of dfi production and the marginal cost of foreign production.

Section 3 extended the equivalence to a general demand system, general market structure, and general mode of market conduct. The restrictive assumption maintained was that of constant marginal costs.

Section 4 relaxed the assumption of constant marginal costs. A numerical counterexample proved that the equivalence of section 3 breaks down under increasing marginal costs.

There are at least two broad areas for extending the analysis presented in this paper. Recent empirical work on strategic trade policy by Dixit (1988) and Baldwin and Krugman (1988) has been restricted to the investigation of price-based policies. The results of this paper should facilitate investigation of quality-based policies when the restrictive assumptions of section 3 apply. The results of this paper are applicable tr an empirical analysis of the current U.S. quota on Japanese automobiles. This is the subject of current research. Finally, this model does not consider dynamic effects of dfi. In an uncertain world, dfi might pre-empt future protectionist trade policy.

\section{References}

Baldwin, Richard and Paul Krugman, 1988, Market access and international competition: A simulation study of $16 \mathrm{~K}$ random access memories, in: R. Feenstra, ed., Empirical methods for international trade (MIT Press, Cambridge).

Bhagwati, Jagdish, 1965, On the equivalence of tariffs and quotas, in: R. Baldwin, ed., Trade, growth, and the balance of payments (Rand McNally, Chicago).

Brander, J. and B. Spencer, 1984, Tariff protection and imperfect competition, in: H. Keirzkowski, ed., Monopolistic competition in international trade (Oxford, New York).

Dixit, A., 1984, International trade policy for oligopolistic industries, Economic Journal 94, $305-312$.

Dixit, A., 1986, Comparative statics for oligopoly, International Economic Review 27, 107-122.

Dixit, A., 1988, Optimal trade and industrial policies for the U.S. automobile industry, in: R. Feenstra, ed., Empirical methods for international trade (MIT Press, Cambridge).

Eaton, J. and G. Grossman, 1986, Optimal trade and industrial policy under oligopoly, Quarterly Journal of Economics 101, 383-406.

Grossman, G., 1984, The gains from international factor movements, Journal of International Economics 17, 73-83. 
Grossman, G. and J.D. Richardson, 1985, Strategic trade policy: A survey of issues and early analysis, International Finance Section, Department of Economics, Princeton University, Special Papers in International Economics, No. 15.

Krishna, K., 1983, Trade restrictions as facilitating practices, discussion papers in economics no. 55, Princeton University, Woodrow Wilson School.

Krugman, P., 1984, Import protection as export promotion, in: H. Kierzkowski, ed., Monopolistic competition and international trade (Oxford University Press) 180-193.

Rodrik, D., 1987, The economics of export performance requirements, Quarterly Journal of Economics 102, 633-650.

Sweeney, G., 1985, Import quotas and oligopolistic interactions, Vanderbilt University Department of Economics Working Paper No. 84-W17. 